\title{
Sociology of Dakwah: \\ Scientific Alternative Social Conflict Resolution Religious
}

By: Nur Kholis, S.Sos.I ,. M.Sosio *

\begin{abstract}
History records since 1789 which lasted throughout the 19th century were confronted by an important event full of chaos, the French Revolution - became the forerunner of human social distortions in dunua at that time. One side of the revolution demonstrate positive change and social order on the other side is going through a critical phase to be part concerns some scientists. However, who would have thought excessive attention and seriousness of the leading scientists cultivated by August Comte and Emile Durkheim. Ultimately leading trigger of Sociology and the validity of the methodology laid Sociology as a science. Who would have thought from then until now, to contribute to the presence of study Sociology 'partnership' as; Political Sociology, Economic Sociology, Sociology of Law, Sociology of Religion, Sociology of Communication and so on. Not without reason that 'partnership' Sociology is a solution of the situation and condition of polemics, discrimination, marginalized, alienation had stripped many aspects of life. Even for a man as the main mission of peace and compassion presenters also increasingly disoriented. It would need to design an alternative social science that is Sociology Propagation, scientific consists of scientific foundation; Sociology itself, the science of Communications and Propagation Studies.
\end{abstract}

Key words: sociology, propaganda, conflict, religious

\section{Pendahuluan}

Eksistensi keilmuan sosial, terutama salah satu cabangnya yakni Sosiologi semakin berkembang di jagad keilmuan. Secara garis besar kita ketahui bersama, bahwa ilmu pengetahuan terdiri atas; pertama, ilmu pengetahuan alam (Sains) sangatlah bersifat statis. Dan ilmu sosial lebih bersifat dinamis meskipun dalam realita - melalui pemikiran, diskusi dan penelitian - seakan masih terkait dengan keadaan statis (mengkaji secara 
struktural). Maka senyatanya, awal kemunculannya Sosiologi dari ilmuwan berkewarganegaraan Perancis, August Comte, dimana Comte sebagai ilmuwan mencoba mensintesa antara ilmu Sains dan Sosial akhirnya menyatakan bahwa berbicara Sosiologi barang tentu mengupas dua hal mengemuka; sosial statis (struktur, lembaga/pranata, lapisan dan stratifikasi sosial) dan sosial dinamis (dinamika atau perubahan sosial).

Sejak awalnya kemunculan Sosiologi, bukan tanpa pertentangan tatkala ilmu tersebut semakin mendapatkan posisinya. Terduga benar, Sosiologi mengancam keilmuan Sains yang kian mengalami pengurangan perhatian 'jamaahnya'. Padahal apabila mampu bersikap bijaksana, meskinya tidak ada satu ilmuwan pun (terutama mereka yang pakar dengan ilmu Sains) menganggap bahwa ilmu yang telah awal mereka cetuskan dianggap kampiun dari ilmu lainnya. Sebelum melangkah lebih jauh, pertarungan keilmiahan sebuah ilmu, maka ada baiknya penulis mengajak pembaca menyimak proses kehadiran ilmu Sains dan ilmu Sosial

Fase perkembangan Sosiologi dunia, bisa diperhatikan melalui penggunaan metode penelitian kualitatif pertama-tama dikenal dalam studi dari Chicago School pada tahun 1910-1940. Selama periode tersebut peneliti dari Universitas Chicago bahkan sampai dengan tahun 1960 mengarahkan penelitian yang dilakukan mereka dengan metode-metode partisipan observation, in-depth interview, dan personal documents. ${ }^{1}$ Pada perkembangan selanjutnya, pemilihan metode penelitian kualitatif bukan saja digunakan dalam studi sosiologi saja melainkan menyebar pada studi bidang politik, sosiologi-antropologi dan psikologi sosial. ${ }^{2}$

Jauh sebelum keilmuan sosial mendapatkan posisinya, maka kedudukan keilmuan dipegang kuat oleh pakar rasional bisa dikatakan dipimpin oleh alur berpikirnya yaitu Plato. Tergolong keilmuan Positivistik (Sains), Plato mempertimbangkan keilmuan terus berpedoman objektif melalui serangkaian data valid dengan perhitungan angka statistik. Tetapi, karena kian problematiknya kondisi kehidupan ternyata angka statistik tidak mampu menganalisa dan memberikan solusinya. Kemudian muncullah sekelompok ilmuwan empirisme dipimpin mulanya oleh Aristoteles mampu memantik kemunculan ilmu sosial bagi kehidupan. Berawal dari mengisi kekosongan dari kajian rasionalisme

\footnotetext{
${ }^{1}$ Bagong Suyanto dan Sutinah (ed), Metode Penelitian Sosial: Berbagai Alternatif Pendekatan, (Jakarta: Kencana, 2011), hal. 166

2 Lihat kata pengantar Nina W Syam pada buku Nina W Syam, Sosiologi Komunikasi, (Bandung: Humaniora, 2009), hal. vii
} 
mendorong empirime bersifat subjektif, untuk lebih melihat sesuatu secara mendalam pada akhirnya problema masyarakat mendapat solusi penyelesaiannya.

Pada konteks Indonesia, awalnya segenap imuwan tergolong pakar ilmu Sosial (salah satunya Sosiologi) terus diperdebatkan kehadirannya oleh ilmuwan Sains. Kondisi dunia sama halnya di Indoesia masih mempertanyakan persoalan endemis, yakni sejauhmana Sosiologi akan bisa memberi arti bagi kesejahteraan umat manusia. Padahal jika diperhatikan secara seksama maka secara keseluruhan unit pembahasan Sosiologi membicarakan urgensi dalam kehidupan manusia; kemiskian di pedesaan, otonomi daerah, proses demokrasi, pendidikan merakyat, disiplin hukum, jaminan hidup selayaknya, konflik dan hal remeh temeh lainnya.

Seakan tidak kunjung usai, melalui pertemuan berangsur-ansur MIPI (Majelis Ilmu Pengetahuan Indonesia, berdiri 1956) mengundang Bung Hatta sebagai pembicara tamu. Dalam pemaparan materinya, Bung Hatta lebih memposisikan diri sebagai pendamai keadaan (peace keeper of situation). Pada kesempatannya, Bung Hatta mengutarakan bahwa pertumbuhan ilmu sosial tidak bisa dilepaskan dari penemuan dan sekaligus masalah sosial yang dihasilkan oleh ilmu-ilmu alam. ${ }^{3} \mathrm{Nah}$, apa yang disampaikan oleh Bung Hatta kiranya bisa dijadikan dasar bahwa sebaiknya antara ilmu Sains (ilmu pengetahuan alam) dan ilmu sosial saling melengkapi satu sama lain. Bukan malahan justru saling menyerang satu sama lain.

Mencoba keluar dari perkembangan keilmuan alam dan sosial telah memiliki pengaruh besarnya di kehidupan. Selanjutnya penulis, mencoba mewacanakan sosiologi yang dipertemukan dengan ilmu dakwah sehingga keilmuan itu lantas disebut Sosiologi Dakwah. Berangkat dari ilmu dakwah telah banyak mendorong banyak pakar, pemerhati dan ilmuwan mulai mengamati, menguraikan, menganalisa dan sampai pada menyimpulkan melalui jurnal, penelitian ilmiah lainnya hingga menerbitkan berbagai buku tentang ilmu dakwah.

Penulis mewacanakan keilmuan Sosiologi Dakwah bukan tanpa alasan. Kita ketahui bersama, ada suatu kondisi terlupakan saat ini, dimana Dakwah menjadi kegiatan setiap manusia untuk menyeru kepada kebaikan dan menjauhi sebuah larangan sang pencipta (Tuhan). Kondisi tersebut mengarahkan manusia pada keteraturan sosial (social order)

3 Tulisan Pendahuluan Taufik Abdulllah dalam buku Taufik Abdullah (ed), Ilmu Sosial dan Tantangan Zaman, (Jakarta: RajaGrafindo Persada, 2006), hal. 2-5 
nantinya menjadi dambaan manusia di kehidupan. Maka oleh sebab itu, kajian dakwah tanpa pandang keagamaan seseorang menjadi misi bersama sebenarnya, dikarenakan menyampaikan hal baik dan menasehati agar terhindar dari hal buruk sebuah keniscayaan manusia menjadi pengingat bagi manusia lainnya.

Saat dipertanyakan bagaimana ilmu dakwah menjadi penguat dalam hubungan sosial. Hal ini bisa diperhatikan bahwa agama melalui proses dakwah selama ini menjadi jalan keluar bagi setiap orang beragama. Perhatikan saja, perjalanan sosiologi menjadi sebuah kedudukan agama tidak bisa dilupakan. Durkheim menulis salah satu karya utamanya tentang moralitas menuju pada keagamaan. Langkah Durkheim diikuti pula Talcott Parsons. Banyak karya Weber juga dicurahkan untuk agama-agama di dunia. Marx pun mempunyai minat terhadap keberagaman, tetapi orientasinya jauh lebih kritis ${ }^{4}$ berujung kepada menyebut "agama sebagai candu".

Memperhatikan semakin pesat pemakaian ilmu dakwah dengan berbagai metodenya baik lisan dan tulisan. Mulanya dakwah diharapkan mampu meneguhkan eksistensi ilmu tersebut untuk semakin memberikan pemahaman tentang agama benar dan baik bagi hambanya. Namun, ternyata seakan tidak luput dari permasalahannya bahwa realita praktis dakwah di masyarakat mengalami kondisi pil pahit (baca: keburukan).

Miris mengetahui menyoroti persatuan umat islam di mana-mana labil dan bahkan pecah. Di tempat tertentu malah benar-benar terpecah seperti di Sampang Madura, terjadinya sesama muslim dan alumni pesantren saling bertingkai dan sampai dengan pembakaran pesantren, rumah tempat tinggal dan menganiaya sesama muslim. ${ }^{5}$ Bahkan isu terhangat terkini, terjadinya konflik Horizontal antara umat Islam dan umat Kristen di Singkil disebabkan adanya sebuah kesalahan pada proses bentukan interaksi sosial secara disosiasi sosial (perpecahan). ${ }^{6}$ Beberapa kasus tersebut menambah deretan polemik, diskriminasi, marginalisasi bahkan alienasi sosial sekelompok orang. Memperhatikan kasus tersebut dilakonkan oleh mereka yang memiliki dasar keilmuan dakwah.

Tatkala dakwah mengalami problematika, berdampak pada terpecah belah manusia dari tingkat lokal, regional sampai dengan

${ }^{4}$ George Ritzer, Teori Sosiologi: Dari Sosiologi Klasik Sampai Perkembangan Terakhir Postmodern, (Yogyakarta: Pustaka Pelajar, 2012), hal. 11-12

${ }^{5}$ Hasbi Amiruddin \& Syukri Syamauan, Dakwah dalam Masyarakat Global, (Banda Aceh: Dinas Syariat Islam Aceh, 2013), hal 97

${ }^{6}$ Serambi Indonesia, Singkil Diambang Konflik SARA, 12/10/2015 
internasional. Itu menandakan keutuhan umat beragama sekalipun terdapat ancaman. Padahal bukan hanya dalam islam saja mestinya kerukunan itu diupayakan oleh pemuka dan pemeluk agama lain turut menjadikan umatnya agar selalu bersatu dalam bingkai perdamaian.

Salah satu dari sekian problema pada perlintasan dakwah tersebut, menjadi bukti bahwa ilmu dakwah pun sedang mengalami kondisi polemik sosio-kultural-religus. Padahal jika mengharapkan keteraturan sosial, maka dakwah menjadi tugas bersama. Oleh karena itu, tulisan singkat ini berupaya untuk menawarkan solusi keteraturan sosial dengan mencetuskan keilmuan dampingan bersama yang disebut dengan Sosiologi Dakwah. Keilmuan tersebut akan memadukan ketiga keilmuan yang telah mendapat pengakuannya yaitu Sosiologi, Ilmu Komunikasi dan Ilmu Dakwah.

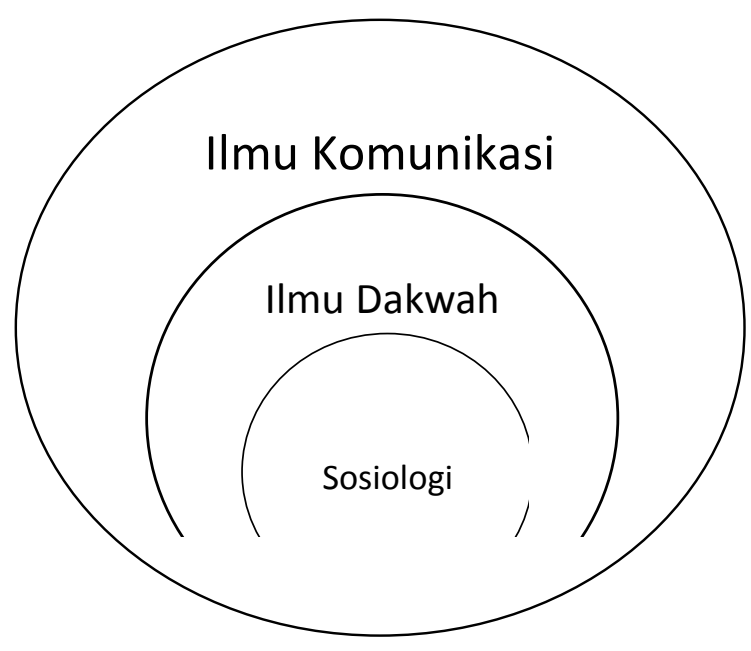

Gambaran Lapisan Keilmuan Sosiologi Dakwah; Sosiologi menjadi inti keilmuan, ilmu Dakwah keilmuan lapisan penguat dan Ilmu Komunikasi menjadi keilmuan penyeimbang

\section{Sosiologi, keilmuan tentang segala hal kebermasyarakatan}

Definisi Sosiologi berasal dari kata sofie, yaitu bercocok tanam atau bertanam, kemudian berkembang menjadi socius, dalam bahasa Latin yang bermakna teman, kawan. Berkembang lagi menjadi social, artinya 
berteman, bersama, berserikat. ${ }^{7}$ Jadi secara pemahaman sederhana maka Sosiologi berarti ilmu yang mempelajari tentang pembentukan realitan sosial, dinamika dan perubahan bagi sekumpulan orang dalam masyarakat.

Awalnya, banyak orang mengkaji Sosiologi secara sempit kebermasyarakatan saja. Padahal dengan mendefinisikan ilmu tersebut secara meluas, maka berbagai situasi dan keadaan yang dialami manusia tidak luput dari perhatian Sosiologi. Bahkan, menariknya Ken Plummer, sebagai Sosiolog ternama yang berasal dari Inggris mengatakan melalui bukunya 'Sosiologi Basics', Sosiologi melakukan pembahasan pada hal remeh temeh pun, seperti kini telah adanya subkajian Sosiologi Tomat, Sosiologi Toilet dan Sosiologi Telepon. ${ }^{8}$ Subkajian ilmu tersebut menambah dereran yang sebelumnya telah ada di anataranya; Sosiologi Pedesaan, Perkotaan, Sosiologi Pendidikan, Sosiologi Hukum, Sosiologi Politik, Sosiologi Agama, Sosiologi Kedokteran, Sosiologi Pembangunan, Sosiologi Wanita, Sosiologi Militer, Sosiologi Kesenian, Sosiologi Bahasa

Keberadaan Sosiologi kian mengalami perkembangan beitu pesat sebegitu menariknya, maka penulis sangat setuju apabila Sosiologi pantas dikatakan sebagai obat mujarab yang menyembuhkan persoalan kehidupan umat manusia. Tatkala harian Kompas menuliskan profil Amartya Kumar Sen, pakar dan ilmuwan Ekonomi sempat meraih Nobel Ekonomi pada tahun 1998. Sang Ilmuwan tersebut ketika mencoba membongkar kemiskinan, menurutnya melihat kemiskinan tidak selalu diperoleh penyebabnya melalui perhitungan statistik. Ternyata yang mesti diperhatikan ialah persoalan sejauhmana pembuat kebijakan (pemerintah atau negara) memanusiakan manusia yakni berbicara kesejahteraan. ${ }^{9}$ Poin kesejahteraan menjadi kata yang hanya ditemukan dari unit kajian sosiologi.

Selain itu, adanya kajian Sosiologi Agama menjadi bukti pula bahwa benar adanya, sosiologi layak didampingkan oleh berbagai kondisi yang mengalami polemik. Dengan adanya disiplin ilmu Sosiologi Agama sebagai keilmuan yang mempelajari ekpresi dalam keberagamaan individu atau sekelompok terajadi dalam tatanan bermasyarakat turut

7 Burhan Bungin, Sosiologi Komunikasi: Teori, Paradigma, dan Diskursus Teknologi Komunikasi di Masyarakat, (Jakarta: Kencana, 2009), hal. 27

${ }^{8}$ Ken Plummer, Sosiologi Basics, (Jakarta: RajaGrafindo Persada,2012), hal 14-18

${ }_{9}^{9}$ Harian Kompas, Amartya Kumar Sen: Membongkar Kemiskinan, edisi 19/01/2014 
menciptakan kerukunan dan damai di kehidupan melalui hal mikro (tindakan) dan makro (struktural). ${ }^{10}$

Selain itu, dapat kita temukan literatur Sosiologi Islam, namun masih sederhana dipikirkan dengan sudut pandang Sosiologi menurut perspektif Islam. Dimana akan kita temukan ilmuwan muslim seperti; Ibnu Abi Rab'i, Al Farabi, Mawardi, Al-Ghazali, Ibnu Taimiyah dan Ibnu Khaldun melalui karya besar mereka telah fokus membicarakan Sosiologi yang akan menyinggung sisi keislamannya. Beberapa ilmuwan tersebut berpijak dengan studi Sosiologi menurut perspektif Islam secara makro, mikro, fungsional dan konflik. ${ }^{11}$

Eksistensi perpaduan sosiologi terhadap kondisi yang mengalami problema sehingga bermunculnya disiplin ilmu bersama, maka inilah yang menjadi dasar pijakan bahwa sosiologi menjadi ilmu yang mampu menembus segala hal demi mengupayakan satu kata yang diharapkan menciptakan kedamaian bagi masyarakat, yaitu kesejahteraan.

Oleh sebab itu, apabila kajian dakwah yang perlu dipedomani bagi setiap umat beragama pun mengalami problematikanya. Itu pertanda, kajian dakwah perlu didampingi oleh keilmuan yang mengarahkan pada kesejahteraan. Tepat apabila sosiologi menjadi sebuah dampingan pada keilmuan dakwah yang sarat pada persoalannya seperti yang dibicarakan pada pembahasan di atas. Kemunculan dari ide menghadirkan Sosiologi Islam saja telah ramai dibicarakan. Apabila ditelusuri akan memunculkan beberapa literatur yang berserakan nantinya. Kendati, telah ada pemikiran menjadikan Sosiologi Islam mengarahkan manusia pada solusi persatuan islam. ${ }^{12}$ Namun, alasan penulis mewacanakan sosiologi dakwah menjadi kajian mengemuka mengatasi problema umat khususnya umat islam yang kian hari mengalami perkembangan mayoritaskan bukan hanya di Indonesia saja bahkan skala dunia.

\section{Ilmu Dakwah sebagai sisi penguatannya}

Mulanya, keilmuan dakwah di Indonesia sempat dipertentangkan melalui diskusi, kuliah umum, dan seminar kajian Islam. dikarenaka sejak mencuat dikemukan oleh beberapa pakar keilmuan Islam, ilmu tersebut belum menemukan cabang keilmuannya; Ontologi, Epistimologi dan Aksiologi. Akan tetapi lambat laun, akhirnya banyak pakar mencoba

\footnotetext{
10 Dadang Kahmad, Sosiologi Agama, (Bandung: Remaja Rosdakarya,2006)., hal. 6

11 Ishomuddin, Sosiologi Perspektif Islam, (Malang: UMM Press, 2005), hal. 5

12 Departemen Agama RI, Islam Untuk Disiplin Ilmu Sosiologi, (Jakarta: Direktorat Jenderal Pembinaan Kelembagaan Agama Islam, 1996), hal. 93
} 
untuk menjelaskan secara mendetail bahwa ontologi ilmu dakwah itu mengarahkan kepada rentangan sejarah nubuwah (kenabian) menyampaikan sesuatu yang menjadi petunjuk, rahmat dan kabar gembira bagi umat muslim sejak dahulu hingga kini, bisa ditelusuri dari surat An-Nahl 89. Kemudian, perihal Epistimologinya ilmu Dakwah bisa ditemukan penjelasannya alam surat Al-Isra ayat 35-36 mengungkapkan bahwa melalui proses empirisnya manusia menemukan apa kebaikan di dunia ini. Dan pada Aksiologi, ilmu Dakwah menjadi keilmuan mesti dipedomani setiap manusia melanjutkan misi penebar perdamaian dan berkasih sayang kepada sesamanya. ${ }^{13}$

Dan kini, telah menemukan keabsahannya, teryata semua disiplin ilmu sosial dapat membantu pengembangan ilmu Dakwah. Ini adalah keharusan dalam ilmu sosial. Sejalan dengan perkembangannya, bahkan ada kemiripan antara ilmu sosial dan ilmu dakwah, dimana ilmu tersebut juga menghadapi permasalahan ekonomi, sosial, kebudayaan, politik, manajemen, hokum dan psikologi. ${ }^{14}$

Pada beberapa referensi buku kajian dakwah, adanya beberapa definisi berkenaan dengan ilmu dakwah di antaranya, sebagai keilmuan yang menghadirkan proses internalisasi, transformasi, transmisi, dan difusi ajaran islam dalam kehidupan masyarakat. ${ }^{15}$ Boleh juga disebut dengan ilmu yang fokus pada upaya atau proses penyampaian ajaran islam baik melalui proses elaborasi islam maupun kondisi konsolidasi. ${ }^{16}$

Dakwah merupakan kegiatan dimana terdapat seorang dai (pendakwah) dan mad'u (jamaah) yang bersosial di dalamnya dengan membawa proses interaksi sosial di dalamnya. Sosial menjadi hal yang tampak pada proses berlagsungnya dakwah. Tatkala dai dan mad'u telah berada dalam area bersama maka ini menjadi penanda hubungan sosial mereka sedang terjalin.

Selanjutnya, definisi dakwah mendekati kesempurnaan maknanya bisa kita telusuri dari pernyataan Ali Hasjmy. Menurutnya dakwah, yaitu usaha untuk mengajak orang lain untuk menyakini dan mengamalkan aqidah dan syariat Islam dengan terlebih dahulu telah diyakini dan diamalkan oleh pendakwah sendiri. ${ }^{17}$

13 Syukriadi Sambas, Landasan Ilmiah Ilmu Dakwah: Perspektif Mizan Al-Quran, makalah disampaikan pada Pelatihan Ilmu Dakwah di Fakultas Dakwah dan Komunikasi UIN ArRaniry pada 04 Desember 2013

14 Moh Ali Aziz, Ilmu Dakwah, (Jakarta: Kencana, 2009), hal. 71

15 Wahidin Saputra, Pengantar Ilmu Dakwah, (Jakarta: RajaGrafindo Persada, 2011), hal. 3

16 Samsul Munir Amin, Ilmu Dakwah, (Jakarta: Amzah, 2013), hal. 29

17 A. Hasjmy, Dustur Dakwah Menurut Al-Quran, (Jakarta: Bulan Bintang, 1994), hal. 17 
Dalam dakwah, perlu mengetahui wasilah dan arena dakwah. Pengertian umum tentang amar maruf dan nahi mungkarm, menyuruh kepada berbuat kebajikan dan kasih saying kepada golongan lemah yang melaksanakan rencana perbaikan akhlak dan masyarakat mencegah berbuat kejahatan dan perbuatan yang merusak akhlak dan masyarakat. Atas dasar inilah, islam mewajibkan atas orang-orang islam untuk membina kesejahteraan masyarakat atas sebaik-baiknya asas kebaikan, sendi akhlak dan gotong-royong. ${ }^{18}$

Sejalan dengan dilibatkan persoalan agama ke dalam masalah kajian sosiologi menjadi hal yang sepatutnya terjadi. Mengingat selama ini, manusia seringkali di saat merasa resah, gelisah dan bimbang dengan apa saja problema kehidupan pada akhirnya menghadirkan jalinan antara hamba dan tuhan demi mengharap ketenangan jiwa. Maka oleh karena itu, menurut penulis ini alasan yang bisa menjelaskan posisi ilmu dakwah sebagai sisi penguat untuk sebuah disiplin ilmu alternaif menyelesaikan masalah seluruh umat beragama di dunia, yaitu sosiologi dakwah.

\section{Komunikasi sebagai sistem penyeimbangannya}

Persoalan komunikasi merupakan problema sangat penting dalam kehidupan dan perkembangan masyarakat primitif, masyarakatsedang berkembang bahkan sampai pada masyarakat modern pula. Oleh sebab itu banyak ahli Sosiologi dan ilmu Sosial lainnya telah menyumbang pikirannya mengenai gejala komunikasi. Lahirnya sejumlah besar definisi yang kadang berbeda, akan tetapi hampir sama maksud dan tujuannya atau tiada berbeda pada inti hahekat keilmuan komuikasi. ${ }^{19}$

Lebih jelas disebutkan, Pentingnya studi komunikasi karena banyak permasalahan yang timbul akibat komunikasi. Manusia tidak bisa hidup sendirian. Ia secara tidak kodrati harus hidup bersama manusia lain, baik demi kelangsungan hidupnya keamanan hidupnya, maupun demi keturunannya. Melalui ilmu komunikasi yang diaplikasikan secara benar akan mampu mencengah dan menghilangkan konflik antarpribadi, antarkelompok, antarsuku, antarbangsa, antarras, demi membina kesatuan kesatuan dan persatuan umat manusia penghuni bumi. ${ }^{20}$

\footnotetext{
18 Ibid, hal. 242

${ }^{19}$ Latief Rousdiy, Dasar-dasar Rhetorica Komunikasi dan Informasi, (Medan: Rimbow, 1989), hal. 47

20 Onong Uchjana Effendy, Ilmu, Teori dan Filsafat Komunikasi, (Bandung: Citra Aditya Bakti, 2003), hal. 27
} 
Komunikasi menjadi proses penyampian pesan dari komunikator (pembicara) ke komunikan (pendengar). Dalam proses berjalannya komunikasi mesti memiliki beberapa unsurnya terdiri dari komunikator dan komunikan menjadi kepastian, pesan, media, dan diharapkan ada umpan balik bersamanya. Tatkala membahas proses interaksi sosial pun ini menjadi prasyarat baginya; kontak sosial dan komunikasi. ${ }^{21}$ Memang kontak sosial menjadi proses awal terjadinya perjumpaan manusia sejak lahir sampai dengan mengalami kematian. Namun, komunikasi pada proses selanjutnya menjadi bagian terpenting. Dikarenakan bukanlah pertemuan atau kontak diri menjadi subtansi bagi manusia satu dan lainnya. Tetapi komunikasi menjadi inti bagaimana pesan tersampaikan dan terus berlanjut pada pengiriman pesan saling menyilang dan pada akhirnya perintah, ajakan dan larangan tersampaikan.

Seperti yang diungkapkan di atas, komunikasi sangat penting dipelajari, darinya manusia mampu menghindarkan diri dari perbedaan makna yang terkadang bukan saja menyebabkan perselisihan bahkan konflik. Beberapa kasus perselisihan efek dari ketidakpahaman komunikasi telah banyak ditemukan di segala kondisi dan peristiwa. Oleh karena, komunikasi menjadi keharusan, bahwa tatkala manusia mampu untuk memahami perbedaan manusia, maka nantiya mampu menghindari konflik. Sedangkan saat manusia justru mampu memahami persamaan mereka ini menjadi jalan manusia semakin mengeratkan hubungan mereka dalam masa depan. ${ }^{22}$

Masih kembali membahas keilmuan dakwah. Kondisi dakwah mengemuka kini, menjadi situasi yang sama peliknya oleh manusia menjalani kehidupan. Kesalahpahaman komunikasi memperjauh jarak hubungan manusia. Tiada berbeda halnya dengan kesalahpahaman manusia dalam berdakwah. Apabila manusia diharuskan menjadikan dakwah sebagai misi setiap umat beragama. Ini berarti, dakwah mesti memunculkan kajian komunikasi untuk membantu penyampaian misi setiap umat tersebut.

Gencar, misi pendakwahan agama dari dua agama terbesar; Islam dan Kristen. Perhatikan dominan kita mengetahui kedua agama tersebut telah banyak manusia menyakini kepercayaan dalam beragama. Bahkan dakwah kedua agama tersebut terkadang saling menyerang untuk semakin menambah penganutnya. Keberkahan kita melihat Negara Eropa

${ }^{21}$ Burhan Bungin: Sosiologi Komunikasi, (Jakarta: Kencana, 2010), hal. 17

22 Deddy Mulyana, Komunikasi Lintas Budaya, (Bandung: Remaja Rosdakarya: 2013), hal.

33 
mencatat setiap tahunnya peningkatan penganut agama Islam di sana. Keberhasilan tersebut tidak akan pernah mampu dilakukan apabila manusia khsususnya umat Islam sendiri tanpa memahami komunikasi.

Memang dapat kita temukan beberapa kesalahan komunikasi, menjadikan misi dakwah menjadi gelisah dan tidak tahu menahu arahnya. Komunikasi terbaik didukung oleh sebuah keadaan berlogika dan empiris. Maksudnya, siapapun manusia pengemban misi dakwah mesti membawa pada penyampaian pesan yang masuk akal (logika) dan mampu menyatakan kebenaran sesuai peristiwa yang terjadi di sekitarnya.

Saat kita masih menemukan situasi dakwah, kian resah dalam lingkup wilayah nasional dan internasional-terjadinya perpecahan umat-. Disanalah sebaiknya perlu diarahkan keilmuan komunikasi agar problema, diskriminasi, marginalisasi, dan alienasi umat beragama mampu diatasi.

Maka seyogyanya, ilmu komunikasi dihadirkan agar menjadi sistem penyeimbang. Tidak akan lengkap rasanya, tatkala kemunculan sosiologi dakwah hanya mengemukakan saja antara keilmuan sosiologi dan ilmu dakwah saja. Memberikan pondasi keilmuan komunikasi kala mewacanakan Sosiologi Dakwah mengakibatkan dakwah nantinya yang menjadi misi setiap umat beragama akan menemukan usaha atau kegiatan penebar perdamaian dan berbagi kasih sayang secara tepat dan jitu di dunia sekalipun.

\section{Kesimpulan}

Dalam perkembangannya, sosiologi yang mengarahkan manusia pada situasi dan kondisi kesejahteraan menjadi hal penting dalam berkehidupan. Manusia berkehidupan dalam berbagai sendi kehidupan; sosial, politik, hokum, budaya, dan agama, jika saja menemukan problema, diskriminasi, marginalisasi dan alienasi. Maka sudah barang tentu akan mencari keilmuan pendamping demi menemukan kesejahteraan. Untuk saat ini, hanya sosiologi menjadi kajian yang tepat mengusahakan kesejahteraan umat manusia. Seperti halnya dakwah, menjadi kegiatan setiap manusia penebar perdamaian dan berbagi kasih sayang tidak luput dari polemiknya. Oleh sebab itu, dakwah yang kini menjadi keilmuan dakwah perlu kiranya bersama sosiologi untuk menjawab dakwah yang terkadang sulit dijalankan umat manusia. Pondasi ketiga keilmuan; sosiologi, ilmu dakwah dan ilmu komunikasi inilah menurut penulis sebagai keilmuan alternative dalam penyelesaian 
berbagai masalah sosial dan keagamaan dalam masyarakat dengan tawaran keilmuan Sosiologi Dakwah.

\section{Daftar Pustaka}

\section{Buku}

Hasjmy. 1994. Dustur Dakwah Menurut Al-Quran. Jakarta: Bulan Bintang Bagong Suyanto dan Sutinah (ed). 2011. Metode Penelitian Sosial: Berbagai Alternatif Pendekatan. Jakarta: Kencana.

Burhan Bungin. 2009. Sosiologi Komunikasi: Teori, Paradigma, dan Diskursus Teknologi Komunikasi di Masyarakat. Jakarta: Kencana. 2010. Sosiologi Komunikasi. Jakarta: Kencana.

Dadang Kahmad. ,2006. Sosiologi Agama. Bandung: Remaja Rosdakarya.

Deddy Mulyana. 2013. Komunikasi Lintas Budaya, (Bandung: Remaja Rosdakarya.

Departemen Agama RI. 1996. Islam Untuk Disiplin Ilmu Sosiologi, (Jakarta: Direktorat Jenderal Pembinaan Kelembagaan Agama Islam.

George Ritzer. 2012. Teori Sosiologi: Dari Sosiologi Klasik Sampai Perkembangan Terakhir Postmodern, (Yogyakarta: Pustaka Pelajar.

Hasbi Amiruddin \& Syukri Syamauan. 2013. Dakwah dalam Masyarakat Global. Banda Aceh: Dinas Syariat Islam Aceh.

Ishomuddin. 2005. Sosiologi Perspektif Islam. Malang: UMM Press.

Ken Plummer. 2012. Sosiologi Basics. Jakarta: RajaGrafindo Persada.

Latief Rousdiy. 1989. Dasar-dasar Rhetorica Komunikasi dan Informasi. Medan: Rimbow.

Moh Ali Aziz. 2009. Ilmu Dakwah. Jakarta: Kencana

Nina W Syam. 2009. Sosiologi Komunikasi. Bandung: Humaniora.

Onong Uchjana Effendy. 2003. Ilmu, Teori dan Filsafat Komunikasi. Bandung: Citra Aditya Bakti.

Samsul Munir Amin. 2013. Ilmu Dakwah. Jakarta: Amzah.

Taufik Abdullah (ed). 2006. Ilmu Sosial dan Tantangan Zaman. Jakarta: RajaGrafindo Persada

Wahidin Saputra. 2011. Pengantar Ilmu Dakwah. Jakarta: RajaGrafindo Persada.

\section{Artikel dan Makalah}

Harian Kompas, Amartya Kumar Sen: Membongkar Kemiskinan, edisi $19 / 01 / 2014$

Serambi Indonesia, Singkil Diambang Konflik SARA, 12/10/2015

Syukriadi Sambas, Landasan Ilmiah Ilmu Dakwah: Perspektif Mizan Al-Quran, makalah disampaikan pada Pelatihan Ilmu Dakwah di Fakultas Dakwah dan Komunikasi UIN Ar-Raniry pada 04 Desember 2013. 